A series of present-day pollen maps is also provided, which is of use as a datum from which the past can be viewed. Also of interest is the principal components analysis and mapping. Here the total data set at each sampling interval is ordinated and the sites mapped according to their scores on each axis. Distinct patterns emerge and can be interpreted on the basis of the loadings of the taxa on each component. In this way the distribution of major vegetation formations at each sample time can be discerned and their changing patterns observed.

The outcome of these analyses and compilations is an excellently presented set of maps which amply rewards careful study. In them one can trace the glacial refugia of our now familiar tree species, and the routes by which they re-invaded central and northern Europe, previously laid bare by glacial and periglacial climates. One can observe the complex vegetation patterns of modern times emerging as a consequence of the interaction between deteriorating climate and the progressive management of the landscape by human beings.

The beech (Fagus), for example, is represented by just a few scattered pollen grains in the Balkans 10,000 years ago. By 6,500 it had managed to reach northern Italy and was squeezing around the east of the Alps into Austria. Then came a surge westwards into southern France, northward through Poland to the Baltic and finally the spread to the north-west and its entry into Britain probably between 3,000 and 4,000 years ago. Archaeologists will no doubt be comparing such movements with cultural developments in Neolithic and Bronze Age Europe to see if its ultimate spread can be linked with primary forest disturbance and secondary invasion.

Pine reached Britain much earlier; certainly by 10,000 years ago. One does, however, gain a distinct impression from these maps that the Scottish population had a separate origin from the English one, the latter being clearly part of a northward movement in Europe, whereas the former seems to be linked with Scandinavia. This should add fuel to the debate, generated by recent cytological work, over the taxonomic affinities of the Caledonian pines.

Presented in simple, graphic form, there is such a wealth of information here that all palynologists will find new insight into their own particular field of interest. The expectancy of past months will now be replaced by an industrious hush in the palynological world as we each work out the implications of these maps for our own pet theories and projects. It is a splendid book, well worth waiting for, and the perfect present for the armchair biogeographer.

Peter D. Moore is Senior Lecturer in the Department of Plant Sciences, King's College, University of London.

\section{Explorations in neurobiology}

\section{Charles F. Stevens}

\section{Membrane Potential-Dependent Ion \\ Channels in Cell Membrane: Phylogenetic and Developmental Approaches. \\ By S. Hagiwara.}

Raven: 1983. Pp.115. \$29.50.

THE world has explorers, those who discover new lands, and map makers, those who chart out what the explorers have found. Although Hagiwara - universally known as Hagi in the trade - has made his share of maps, he is one of neurobiology's foremost explorers, and with this book has given us a journal, written retrospectively, of his travels. He writes in the first person, informally and clearly, and not only describes what he has discovered, but also what he was searching for, why, and what he thought about the things he turned up.

Hagiwara has had an important role in the development of neurobiology and membrane biophysics in many ways, but two of his general influences require special note. First, he has been a leader in informing neurobiologists of the value of a comparative approach. Not so many years ago, a prejudice was abroad among brain scientists that studies of lower organisms are largely irrelevant for revealing the mysteries of nervous systems such as our own. A few invertebrates - the squid, for example - were awarded honorary mammalhood, but mostly invertebrate and non-mammalian vertebrates were tacitly considered unworthy. Hagi, together with

\section{Chromosome cookery}

\section{Michael Ashburner}

Working with Animal Chromosomes.

By Herbert Macgregor

and Jennifer Varley.

Wiley: 1983. Pp.250. £17.50, \$33.

RECIPE books have a long and distinguished history. Mrs Beeton's Cookery and Household Management has set many a married couple on the path to conjugal bliss, a path made smoother by good cooking. Macgregor and Varley now offer, to a rather narrower audience than Mrs B, Working with Animal Chromosomes. Their intention is "to describe in detail ways of working with chromosomes that are most useful for tackling current problems relating to the organization, function and behaviour of the genome in eukaryotic cells". Nearly half of the book is devoted to giant chromosomes - the polytene chromosomes of flies (but not, alas, of protozoa) and lampbrush
Kuffler and others, showed us that the systems that best reveal the properties of the brain can be invertebrate neurones or certain cells (such as eggs) that are not even neuronal.

To understand Hagiwara's second main area of influence, one must appreciate the situation in neurobiology about 1960 . Intracellular recording was just starting to be widely used for a variety of different systems, and voltage clamp studies were rare. In those days all neuronal membranes were simple things, equipped with only the Hodgkin-Huxley sodium and potassium channels. We now know, of course, that the brain's electrical activity depends upon a great number of different channel types. This insight depended in large part on results of Hagiwara's studies described in his new book.

The book itself is not long, just over 100 pages which are divided into five main chapters, with a brief introduction and conclusion. These chapters focus on properties of voltage gated sodium, calcium and potassium channels, and the descriptions appropriately centre on Hagiwara's own work - most of the figures are, for example, from his papers - although other contributions are not neglected. The writing is straightforward and easy to understand, but this is not a book for the casual reader who wants to learn something about the importance of channels to our understanding of brain function. Those who study channel function, however, will want to read this illuminating, personal account of Hagiwara's contributions of the past quarter century.

Charles F. Stevens is Chairman of the Section of Molecular Neurobiology at Yale University School of Medicine. chromosomes, especially those of the amphibian oocytes. This emphasis reflects the authors' own research interests and, of course, their aims.

The analogy between cooking and cytological techniques is a good one. Both demand a degree of flair and extensive practice. Both can be learnt from books, but should be learnt from a master. For both, some appreciation of the underlying chemical and physical principles is a help, but many of the best cooks, and cytologists, use intuition and "feel", rather than science, in their art. At the very best any recipe book can only inform the reader that some techniques are possible and that close attention to the recipe will produce a result that is broadly successful. To do more will require practice.

Macgregor and Varley have quite deliberately not attempted to be comprehensive nor have they included any serious consideration of the theoretical background to the methods they describe. I would support the selectivity of their coverage; once a basic technique has been learnt it is usually quite easy to pick up a 